\title{
Psychometric properties of the Hungarian version of the adult ADHD self-report scale (asrs-v1.1) screener and symptom checklist
}

\author{
Susana Farcas*1, Kinga Kálcza-Jánosi ${ }^{1}$, Ibolya Kotta ${ }^{1}$, Kinga Szabó ${ }^{1}$, Réka János ${ }^{1}$ \\ ${ }^{1}$ Babes-Bolyai University, Department of Applied Psychology, Cluj-Napoca, Romania \\ *Corresponding author: susana.farcas@ubbcluj.ro
}

\begin{abstract}
.
Objectives. In the present study the utility and psychometric properties of the Hungarian version of the Adult ADHD Self-Report Scale (ASRS-v1.1) was investigated. The purpose was to translate and to adapt the ASRS-v1.1 screener (6-item) and the Symptom Checklist (18-item). In addition, no previous studies assessed prevalence of ADHD symptoms of Hungarian adults from Romania.

Methods. A total of 1,503 adults were evaluated. The mean age of participants was $\mathrm{M}(\mathrm{SD})=23.98(57.26)$ years, between $18-44$ years, 37.7\% ( $\mathrm{N}=567)$ were male participants, $69.4 \%$ from Romania $(\mathrm{N}=1,043)$ and $30.6 \%$ from Hungary $(\mathrm{N}=460)$. 100-100 participants from the positive and negative result group were randomly selected for confirming diagnosis.

Results. The CFA indicated adequate fit to the structure proposed by the DSM-IV in the 18-item version. The ASRS-v1.1 maintained its two-factor structure model of inattention ( 9 items) and hyperactivity/impulsivity (9 items). Furthermore, the subscales of the 18-item ASRS-v1.1 exhibited good internal consistency indicated by acceptable Cronbach's alpha (inattention subscale $\alpha=.84$, hyperactivity subscale $\alpha=.80$, total $\alpha=.88$ ). Reliability values of the ASRS-v1.1 screener were less adequate than the symptom checklist. According to the results, the 6 item ASRS-v1.1 had fair internal consistency (inattention subscale $\alpha=.77$, hyperactivity subscale $\alpha=.54$, total $\alpha=.72$ ).

Unweighted prevalence of AD, based on the ASRS-v1.1 symptom checklist, was $1.5 \%(\mathrm{~N}=23)$. Moreover, $1.2 \%$ of the assessed population seems to have HD, mostly female participants $(0.8 \%)$. In addition, $4.5 \%$ seems to have ADHD ( $\mathrm{N}=67)$, mostly male $(2.5 \%)$. The screener identified $37.3 \%(\mathrm{~N}=561)$ of the total assessed population as highly likely to have ADHD.

The Area Under Curve for the ASRS-v1.1 6 item was AUC=.99 (95\% CI: .98-1.00), while for the 18 item ASRS-v1.1 was AUC=1.00.

Conclusions. Results suggest that the 18 item ASRS-v1.1 is a good symptom checklist for the assessment of adult ADHD, indicated by the good psychometric properties of the scale. In addition, the ASRS-v1.1 screener can be considered a fair screening tool for identifying symptoms of ADHD among normal population.
\end{abstract}

Keywords: adult ADHD, ASRS-v1.1 screener, ASRS-v1.1 symptom checklist, confirmatory factor analysis

\section{Introduction}

Attention-Deficit/Hyperactivity Disorder (ADHD) can be considered one of the most common neurodevelopmental disorders among children and often persists into adulthood (APA, 2013). The prevalence of the adult ADHD persistence strongly depends on diagnostic criteria. Several studies reported the prevalence of adult ADHD between 2.9\%-3.2\% based on DSM-IV, full 
criteria diagnosis. Results from the National Comorbidity Survey Replication indicate that ADHD prevalence in adults aged 18-44 years in the United States is approximately 4.4\%. Using a two-part diagnostic interview there were 3199 cases of adult ADHD identified (Kessler et al., 2006). The pooled prevalence of adult ADHD according to the meta-analysis of Simon et al. (2009) was $2.5 \%$ (95\% CI 2.1-3.1). According to the results, the prevalence decreased with age when gender proportion was controlled. In a German community sample aged 18-64 years $(\mathrm{N}=$ 1,655) the estimated crude prevalence rate of ADHD was 4.7\%. Adult ADHD was significantly associated with lower age, low educational level, unemployment, marital status (never married and divorced), and rural residency (de Zwaan et al., 2012). Mean worldwide prevalence of ADHD is estimated at 2.8\% (range 0.6-7.3\%) in adults (Fayyad et al., 2017).

There are few previous studies assessing the prevalence of ADHD symptoms in Hungarian adults from Romania. Results have been reported from both countries separately, from Romania respectively from Hungary.

Research of van de Glind et al. (2014) a cross-sectional study, assessed substance use disorder (SUD) patients in 10 countries, a two stage international multi-center - from inpatient and outpatient addiction treatment centers for alcohol and/or drug use disorder patients. A total number of 3,558 treatment seeking SUD patients were screened for adult ADHD. A subsample of 1,276 subjects, both screen positive and screen negative patients, participated in a structured diagnostic interview. According to van de Glind et al. (2014) results the prevalence of adult ADHD for Hungary, based on DSM-IV and DSM-5 criteria varied from 5.4\% (CI 95\%: 2.4-8.3) to $7.6 \%$ (CI 95\%: 4.1-11.1), slightly higher for DSM-5.

One epidemiological study focused on the prevalence of ADHD in a Hungarian community sample $(\mathrm{N}=3,529)$, aged between 18 and 60 years. 279 subjects screened positively and finally 161 subjects participated in a clinical interview to confirm the diagnosis. Bitter et al. (2017) reported prevalence of 1.3 to $4.6 \%$ (threshold-subthreshold) of adult ADHD in Hungary. Crude prevalence estimates adjusted for the specificity and sensitivity data of the screener were $1.35 \%$ in the 'DSM-IV' group. Prevalence estimates corrected for the 'not-interviewed' subsample and adjusted for specificity and sensitivity data of the screener was $2.3 \%$ in males, $0.91 \%$ in females; $2.02 \%$ in the $<$ or $=40$ years age group and $0.70 \%$ in the $>40$ years age group, based on DSM-IV diagnostic criteria (Bitter et al., 2010).

Fayyad et al. (2017) reported data of adult ADHD based on WMH surveys. The Composite International Diagnostic Interview (CIDI) was administered to 26,744 respondents, allocated to 3 groups based on countries income: high-, upper-middle-, and low-/lower-middle-income countries (68.5\% mean response rate). Results showed $2.8 \%$ prevalence of adult ADHD. In addition, prevalence was higher in high (3.6\%)- and upper-middle (3.0\%)- than low-/lowermiddle (1.4\%)-income countries. Romania was allocated to the upper-middle-income countries. Multiply imputed prevalence estimates of DSM-IV/CIDI of adult ADHD in Romania was 0.6\%, based on 940 adults in the total sample (Fayyad et al., 2017).

However, there seems to be controversy surrounding the results, because existing epidemiological studies vary widely in assessment tools, classification systems, and data collection procedures across countries. Comparing cross-national results is somewhat difficult.

Although, there are a number of available screening instruments for adult ADHD (Das et al., 2012, Faraone, Antshel, 2008), the ASRS-v1.1 is one of the most promising screening tool currently in use (Kim et al., 2013).

The Adult ADHD Self-Report Scale (ASRS-v1.1) (available: https://www.hcp.med.harvard.edu/ncs//ftpdir/adhd/adhd/) was developed jointly by the WHO 
and Adler, Spencer et al. (2005) as part of the Composite International Diagnostic Interview CIDI. The 18-item scale is based on the diagnostic criteria of the Diagnostic and Statistical Manual of Mental Disorders (DSM-IV) of the American Psychiatric Association (APA, 2000). The 6-item ASRS-v1.1 (Kessler et al., 2005, Kessler et al., 2006) is a subgroup of the ASRSv1.1 Symptom Checklist. The 6-item ASRS-v1.1 screener (Kessler et al., 2007) was designed as an instrument to help screen for ADHD in adults (aged 18 years and older) and are consistent with the diagnostic criteria and address manifestation of ADHD in adults. Respondents have to indicate the frequency of occurrence of symptoms using a 5 point Likert scale to ranging from 0 to 4 ( $0=$ never; 1 =rarely; $2=$ sometimes; $3=$ often; $4=$ very often $)$.

Research focus on different clinical and nonclinical population and collect information regarding ADHD symptoms using the ASRS-v1.1. Considerable progress has been made with regard to the psychometric properties of the tool analyzed in several translated versions: Arabic, Chinese (Yeh et al., 2008), Danish, Dutch, French (Morin, Tran, Caci, 2016), Finnish, German, Hebrew, Japanese, Korean (Kim et al., 2013), Norwegian, Portuguese, Spanish (Pedrero, Puerta, 2007), Thai translations and adaptations in several samples.

Kessler et al. (2005) analyzed the psychometric properties of the ASRS in the general population $(\mathrm{N}=154)$. According to the results the unweighted 6 item ASRS screener outperformed the unweighted 18 item ASRS symptom checklist in sensitivity (68,7\% v. 56,3\%), specificity $(99,5 \%$ v. $98,3 \%)$, total classification accuracy $(97,9 \%$ v. 96,2\%), and $\kappa(.76$ v. .58).

In a pilot study by Adler et al. (2007) adults ( $\mathrm{N}=60)$ with ADHD diagnosis were asked to complete the ASRS and then the raters administered the standard ADHD RS. Internal consistency of both instruments was high (indicated by high Cronbach alpha values $\alpha=.88$, respectively $\alpha=89$ ). The Intraclass Correlation Coefficient between scales for total scores was also high ( $\mathrm{ICC}=.84$ ), with acceptable agreement for individual items (\% agreement: 43\%-72\%) and significant kappa coefficients for all items $(\mathrm{p}<0.001)$.

Further studies assessed a sample of health plan members $(\mathrm{N}=668)$ in the US with the 6 item ASRS screener. Internal consistency was fair: .63-.72, test-retest reliability (Pearson correlations) was acceptable .58-.77 (Kessler et al., 2007).

Previous studies reported good test-retest reliability and internal consistency of the translated versions of the ASRS-v1.1 Symptom Checklist. Psychometric properties of the Korean version of the ASRS-v.1.1 were good (Kim et al., 2013). Based on a community sample of 205 individuals according to the results the ASRS had good internal consistency (indicated by high Cronbach alpha value $\alpha=.885)$ and test-retest reliability $(\alpha=.878)$. In addition, a subsequent exploratory factor analysis indicated that a two factor solution provided the best fit.

The Chinese version of the ASRS (Yeh et al., 2008) assessed ADHD symptoms in a sample of 1,031 young males from an army base and 3298 young adults from college. Results showed good concordance (ICC=.80 v. .85) and internal consistency (Cronbach alpha $\alpha=.83$ v. .91) of the ASRS subscales and moderate to high correlations between these subscales and the WURS (Pearson's correlations $=.37$ v. .66).

Morin, Tran, Caci (2016) examined a French community sample of 1,171 adults. The main purpose was to assess the factor structure, reliability and measurement invariance of the ASRS tool. Results support a bifactor model of the ASRS, including one general ADHD factor and three specific: inattention, hyperactivity, and impulsivity factor. Results also support measurement invariance across gender and age groups. In addition, gender differences were pointed out: men reported higher scores than women on the ADHD general factor, but lower 
scores on all three specific factors. According to Morin et al. (2016) results suggest that a total ADHD score is meaningful, reliable, and valid in adults.

Carlucci et al. (2017) assessed the validity and reliability of the ASRS-v1.1 in a clinical sample with eating disorders $(\mathrm{N}=500)$. A confirmatory factor analysis was conducted: the CFA indicated a bifactorial structure of inattention and impulsivity/hyperactivity symptoms. The item loadings exhibited path invariance across ED diagnostic groups, indicated good construct validity. Furthermore, the ASRS-v1.1 subscales showed good internal consistency and significantly correlated with other measures of ADHD indicating fair convergent validity.

Kiatrungrit et al. (2017) investigated the psychometric properties of the Thai version of the ASRS-v1.1, as a screening tool for adult ADHD. 1,500 parents of kindergarten and elementary school students in Bangkok, Thailand completed the scale. 816 of them were returned (54.4\%). There were 52 and 764 participants who had positive and negative screening results, respectively. 50-50 parents were randomly selected from the positive and the negative result group for confirming diagnosis. The clinical interview was run by 3 psychiatrists who were blinded to the results and used DSM-5 ADHD criteria for diagnosis. Based on the results the 18 item ASRS-v1.1 TH had satisfactory internal consistency (indicated by high Cronbach alpha value $\alpha=.92$, respectively $\alpha=.87$ for inattentive scale, $\alpha=.84$ for hyperactive/impulsive scale). The Area Under Curve for the ASRS 6 item was AUC=.80 (95\% CI: .68-.92), while for the 18 item ASRS was AUC=.71(95\% CI: .55-.86).

Stanton et al. (2018) examined the factor structure of the adult ASRS-v1.1 in a large sample of adult outpatients $(\mathrm{N}=1,094)$. The ASRS-v1.1 was used (Kessler et al., 2005) as a self-report ADHD measure. Results indicated that the ASRS's items define a bifactor structure with specific dimensions of inattentiveness, motor hyperactivity/impulsivity and verbal hyperactivity/impulsivity.

Results so far have been very promising, encouraging practitioners to use the ASRS tool for adult ADHD screening, as a valid and reliable instrument. Despite this, taking into consideration previous studies results, the use of the 18 item version versus the 6 item version raises questions among clinicians and researcher. Thus, two main aims were set for the current study. The first aim of the present study was to investigate the utility and psychometric properties of the Adult ADHD Self-Report Scale (ASRS-v1.1) in a Hungarian sample, comparing results of Hungarian adults from Romania and from Hungary. No studies have been published translating the current tool into Hungarian language. Therefore a study has been carried out in order to analyze the translated and adapted ASRS tool. The translation protocol and guidelines of the WMH-CIDI were followed. The secondary aim of the current study was to assess prevalence of adult ADHD in Hungarian adults from Romania and from Hungary.

\section{Methods}

\subsection{Participants}

Inclusion criteria: participants were adults (between ages 18-44 years), mostly healthy university students or recruited from the general community population. Participants completed the self-reported scales online. A total of 1,503 adults were evaluated with the ASRS-v1.1 screener and symptom checklist. The mean age of participants was $\mathrm{M}(\mathrm{SD})=23.98(57.26)$ years, 
between 18-44 years, 37.7\% ( $\mathrm{N}=567)$ were male participants. Moreover, $69.4 \%(\mathrm{~N}=1043)$ of the participants were Hungarian adults from Romania and 30.6\% from Hungary $(\mathrm{N}=460)$.

\subsection{Instruments}

The 6-item ASRS-v1.1 screener and the18-item ASRS-v1.1 Symptom Checklist (Kessler et al., 2005; Kessler et al., 2006) was used. Symptom frequency was rated on a 5 point Likert scale to indicate the frequency of occurrence of symptoms $(0=$ never; $1=$ rarely; $2=$ sometimes; $3=$ often; 4 = very often). Items are allocated into two main groups, based on symptoms: items number 1, 2, 3, 4, 7, 8, 9, 10, 11 symptoms of inattention and items number 5, 6, 12, 13, 14, 15, 16, 17, 18 hyperactivity, impulsivity symptoms. The ASRS-v1.1 was translated into Hungarian according to WHO World Mental Health initiative interview translation guidelines. (The process included forward-backward translation. After a pilot study, modifications and adjustments were made for the final version.). The clinical interview for confirming diagnosis was run by 4 clinical psychologists who were blinded to the results. 100 participants were randomly selected from the positive result group and 100 from the negative result group. The clinical interview was conducted via telephone by the clinical psychologists. The structured Diagnostic Interview for Adult ADHD, DIVA 2.0 was used, which is based on the criteria for ADHD in DSM-IV., available online http://www.divacenter.eu/DIVA.aspx?id=505).

\section{Results}

\subsection{Descriptive statistics}

Descriptive statistics are presented in Table 1.

Table 1. Demographic data of the participants

\begin{tabular}{|c|c|c|}
\hline \multicolumn{2}{|l|}{ General information } & $\begin{array}{l}\text { Total sample } \\
(\mathrm{N}=\mathbf{1 , 5 0 3})\end{array}$ \\
\hline Mean age (SD) & & $23.98(5.257)$ \\
\hline \multirow{2}{*}{ Gender N(\%) } & Male & $567(37.7 \%)$ \\
\hline & Female & $936(62.3 \%)$ \\
\hline \multirow[t]{5}{*}{ Education level N(\%) } & Elementary school & $63(4.2 \%)$ \\
\hline & High school & $409(27.2 \%)$ \\
\hline & University & $586(39 \%)$ \\
\hline & Other & $130(8.6 \%)$ \\
\hline & Not reported & $315(21 \%)$ \\
\hline \multirow[t]{4}{*}{ Occupation N(\%) } & Student & $871(58 \%)$ \\
\hline & Working, has a job & $443(29.5 \%)$ \\
\hline & Student with part time job & $162(10.8 \%)$ \\
\hline & Other & $27(1.8 \%)$ \\
\hline \multirow[t]{2}{*}{ Residence N(\%) } & Rural & $615(40.9 \%)$ \\
\hline & Urban & $888(59.1 \%)$ \\
\hline \multirow[t]{2}{*}{ Country N(\%) } & Romania & $1043(69.4 \%)$ \\
\hline & Hungary & $460(30.6 \%)$ \\
\hline
\end{tabular}

Firstly, in order to determine the construct validity of the scales the distribution was checked, see Table 2 for Skewness and Kurtosis values. The values for asymmetry and kurtosis between -2 and +2 are considered acceptable in order to prove normal univariate distribution (George, Mallery, 2010). 


\subsection{Reliability/Internal consistency}

The subscales of the 18-item ASRS-v1.1 Symptom Checklist exhibited good internal consistency indicated by acceptable Cronbach's alpha: inattention subscale $\alpha=.84$, hyperactivity subscale $\alpha=.80$, total $\alpha=.88$. Despite this, the psychometric properties of the ASRS-v1.1 screener were less adequate than the 18 item ASRS. This version had fair internal consistency: inattention subscale $\alpha=.77$, hyperactivity subscale $\alpha=.54$, total $\alpha=.72$.

\subsection{Construct Validity}

A Confirmatory Factor Analysis (CFA) was conducted using the SPSS AMOS package. A bifactorial model was tested (see Figure 1 and 2). The Maximum Likelihood procedure was used. A guidelines for interpreting the results of the model fit indices are the following: for the CFI-Comparative Index (Bentler, 1990) and the GFI-goodness-of-fit index (GFI), acceptable values are close to or greater than .90-.95; the RMSEA values- the root-meansquare error of approximation (Steiger, Lind, 1980) must be less than .08, indicating a good fit of the model, or lower than .05 excellent fit, and the values close to or equal to 0.08 indicate a reasonable match (Browne, Cudeck, 1989). According to the results of the current study, the 2 factor structure model are adequate, indicated by the model fit indices below (see Table 2).

Table 2. Model Fit Indices

\begin{tabular}{|c|c|c|c|c|c|c|c|c|}
\hline & Constructs & $\Delta \chi^{2}$ & $\Delta d f$ & $p$ & CFI & PCFI & $\begin{array}{l}\text { TLI } \\
\text { rho2 }\end{array}$ & RMSEA \\
\hline $\begin{array}{l}\text { ASRS-v1.1 Symptom } \\
\text { Checklist (Figure 1A) }\end{array}$ & $\begin{array}{l}2 \text { factor structure/ a } \\
\text { total of } 18 \text { items }\end{array}$ & 1237.079 & 134 & .000 & .861 & .754 & .842 & .074 \\
\hline $\begin{array}{l}\text { ASRS-v1.1 screener } \\
\text { (Figure } 1 B \text { ) }\end{array}$ & $\begin{array}{l}2 \text { factor structure/ } a \\
\text { total of } 6 \text { items }\end{array}$ & 39.053 & 8 & .000 & .983 & .524 & .968 & .051 \\
\hline
\end{tabular}

Analyzing the model fit indices, the ASRS screener outperforms the 18 item symptom checklist, indicated by the excellent CFI and RMSEA values.

The Spearman's rho correlation value between the 6 item screener and the 18 item symptom checklist is high .916 - the value indicating a strong relation between the scores.

\subsection{Criterion validity}

The strength of association between the 6 item ASRS-v1.1 and the 18 item ASRS-v1.1 total score with a clinical diagnosis was assessed by calculating the area under curve (AUC) of the receiver operating characteristic (ROC) and to determine the proper sensitivity and specificity of the questionnaire for the best cut-off score.

The Area Under Curve for the ASRS 6 item was AUC=.99 (95\% CI: .98-1.00), while for the 18 item ASRS-v1.1 was AUC=1.00. The cutoff scores used were as following for the ASRS 18 item: scores between 0-16 unlikely to have ADHD, scores 17-24 likely to have ADHD, above 24 highly likely to have ADHD, and for the ASRS 6 item: scores between 0-4 unlikely to have ADHD, scores 5-11 likely to have ADHD, above 12 highly likely to have ADHD. Based on these scores sensitivity for the 6 item ASRS-1.1 was $93 \%$ and $100 \%$ specificity (for scores above 12). In addition, sensitivity for the 18 item ASRS-1.1 was $100 \%$ and $99 \%$ specificity (for scores above 24). 

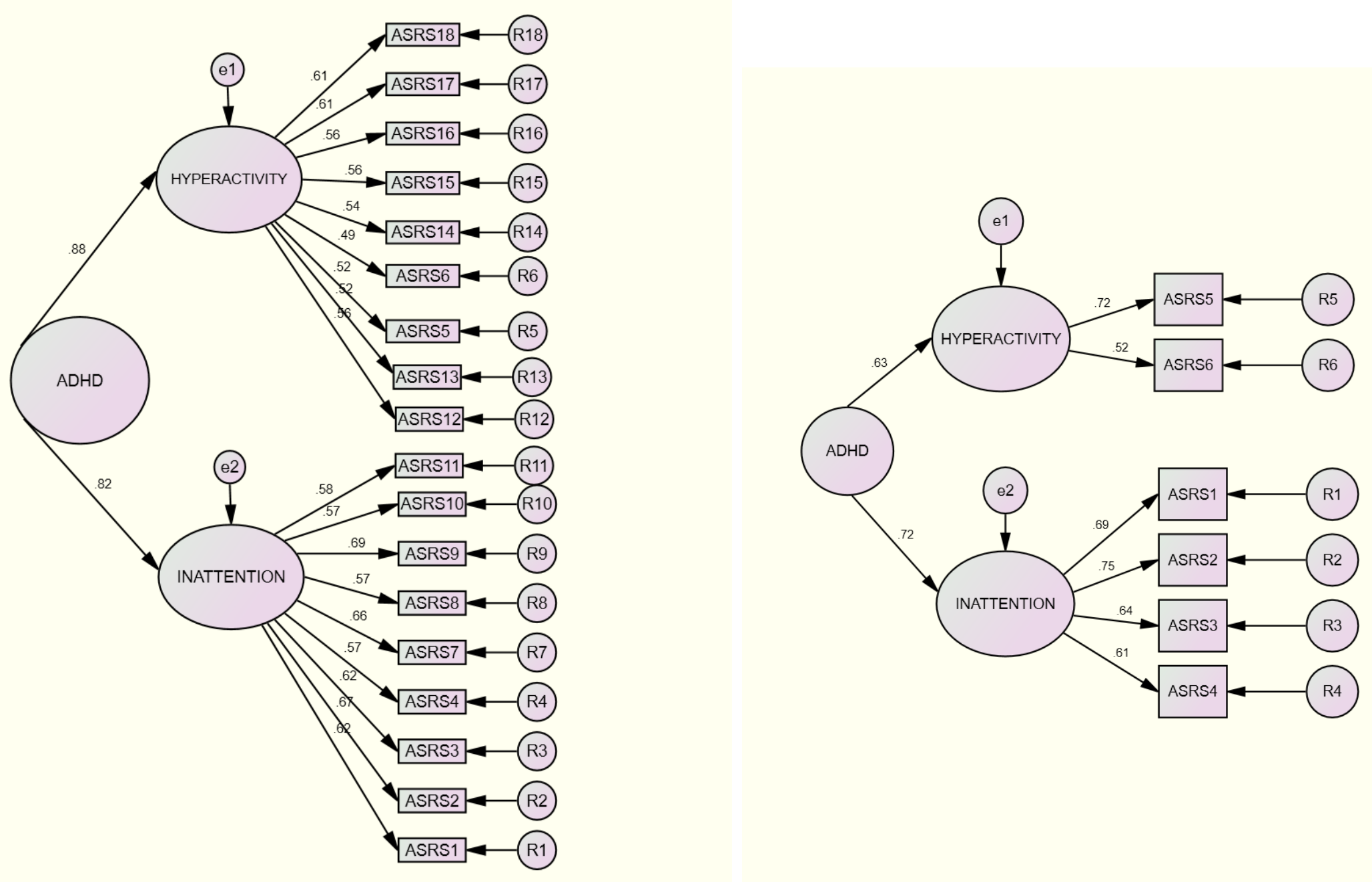


\subsection{Prevalence of ADHD}

Chi square was used to assess the association between gender and ADHD symptoms, results were significant (see Table 3).

Table 3. Prevalence of ADHD symptoms and gender association

\begin{tabular}{|c|c|c|c|c|c|c|c|c|c|c|}
\hline \multicolumn{11}{|c|}{ ASRS-v 1.1 Symptom Checklist (18-item) } \\
\hline \multirow{4}{*}{ Gender } & \multirow{3}{*}{ Male } & & $\begin{array}{l}\text { unlikely to } \\
\text { have } \\
\text { ADHD }\end{array}$ & $\begin{array}{l}\text { likely } \\
\text { to have } \\
\text { HD }\end{array}$ & $\begin{array}{l}\text { likely to } \\
\text { have } \\
\text { AD }\end{array}$ & $\begin{array}{l}\text { likely to } \\
\text { have } \\
\text { ADHD } \\
\text { C }\end{array}$ & $\begin{array}{l}\text { highly } \\
\text { likely } \\
\text { to have } \\
\text { AD }\end{array}$ & $\begin{array}{l}\text { highly } \\
\text { likely } \\
\text { to have } \\
\text { HD }\end{array}$ & $\begin{array}{l}\text { highly } \\
\text { likely to } \\
\text { have } \\
\text { ADHD } \\
\text { C }\end{array}$ & Total \\
\hline & & $\mathrm{N}$ & 229 & 83 & 90 & 111 & 10 & 6 & 38 & 567 \\
\hline & & $\begin{array}{l}\% \text { of } \\
\text { Total }\end{array}$ & $15.2 \%$ & $5.5 \%$ & $6.0 \%$ & $7.4 \%$ & $.7 \%$ & $.4 \%$ & $2.5 \%$ & $37.7 \%$ \\
\hline & \multirow[t]{4}{*}{ Female } & $\mathrm{N}$ & 441 & 137 & 118 & 186 & 13 & 12 & 29 & 936 \\
\hline \multirow{3}{*}{ Total } & & $\begin{array}{l}\% \text { of } \\
\text { Total }\end{array}$ & $29.3 \%$ & $9.1 \%$ & $7.9 \%$ & $12.4 \%$ & $.9 \%$ & $.8 \%$ & $1.9 \%$ & $62.3 \%$ \\
\hline & & $\mathrm{N}$ & 670 & 220 & 208 & 297 & 23 & 18 & 67 & 1503 \\
\hline & & $\%$ of & $44.6 \%$ & $14.6 \%$ & $13.8 \%$ & $19.8 \%$ & $1.5 \%$ & $1.2 \%$ & $4.5 \%$ & $100.0 \%$ \\
\hline
\end{tabular}

Pearson Chi square $\quad \chi 2(6)=17.08, p=.009$

Cramer's V =.107, p=.009

\begin{tabular}{|c|c|c|c|c|c|c|}
\hline \multicolumn{7}{|c|}{ ASRS-v1.1 screener (6-item) } \\
\hline \multirow{4}{*}{ Gender } & \multirow[b]{2}{*}{ Male } & \multirow[b]{2}{*}{$\mathrm{N}$} & \multirow{2}{*}{$\begin{array}{l}\text { unlikely to } \\
\text { have } \\
\text { ADHD } \\
86\end{array}$} & \multirow{2}{*}{$\begin{array}{l}\text { likely } \\
\text { to have } \\
\text { ADHD } \\
235\end{array}$} & $\begin{array}{l}\text { highly } \\
\text { likely to } \\
\text { have } \\
\text { ADHD }\end{array}$ & Total \\
\hline & & & & & 246 & 567 \\
\hline & & $\begin{array}{l}\% \text { of } \\
\text { Total }\end{array}$ & $5.7 \%$ & $15.6 \%$ & $16.4 \%$ & $37.7 \%$ \\
\hline & Female & $\mathrm{N}$ & 148 & 473 & 315 & 936 \\
\hline \multirow{3}{*}{\multicolumn{2}{|c|}{ Total }} & $\begin{array}{l}\% \text { of } \\
\text { Total }\end{array}$ & $9.8 \%$ & $31.5 \%$ & $21.0 \%$ & $62.3 \%$ \\
\hline & & $\mathrm{N}$ & 234 & 708 & 561 & 1503 \\
\hline & & $\begin{array}{l}\% \text { of } \\
\text { Total }\end{array}$ & $15.6 \%$ & $47.1 \%$ & $37.3 \%$ & $100.0 \%$ \\
\hline \multicolumn{7}{|c|}{ Pearson Chi square $\quad \chi 2(6)=15.246, p=.000$} \\
\hline \multicolumn{7}{|c|}{ Cramer's V =.101, p=.000 } \\
\hline
\end{tabular}

Note. $H D=$ hyperactivity disorder, $A D=$ attention disorder

Based on the ASRS-v1.1 18 item symptom checklist, 1.5\% of the participants $(\mathrm{N}=23)$ reported attention problems (allocated to the highly likely to have attention disorder group), and $1.2 \%$ of the assessed population reported hyperactivity symptoms (allocated to the highly likely to have hyperactivity disorder group), mostly female (0.8\%). In addition, $4.5 \%$ were allocated to the highly likely to have ADHD Combined type group ( $=67)$, mostly male $(2.5 \%)$.

Based on ASRS-v1.1 6 item screener the unweighted prevalence of the ADHD symptoms (allocated to the highly likely to have ADHD group) was $37.3 \%(\mathrm{~N}=561)$.

The Cramer's V coefficient provides a measure of the strength of the association between the variables, the effect size is 0.1 , indicating a small effect size.

See Figure $2 \mathrm{~A}$ and $2 \mathrm{~B}$ for visual graphic of the unweighted prevalence regarding gender distribution. 


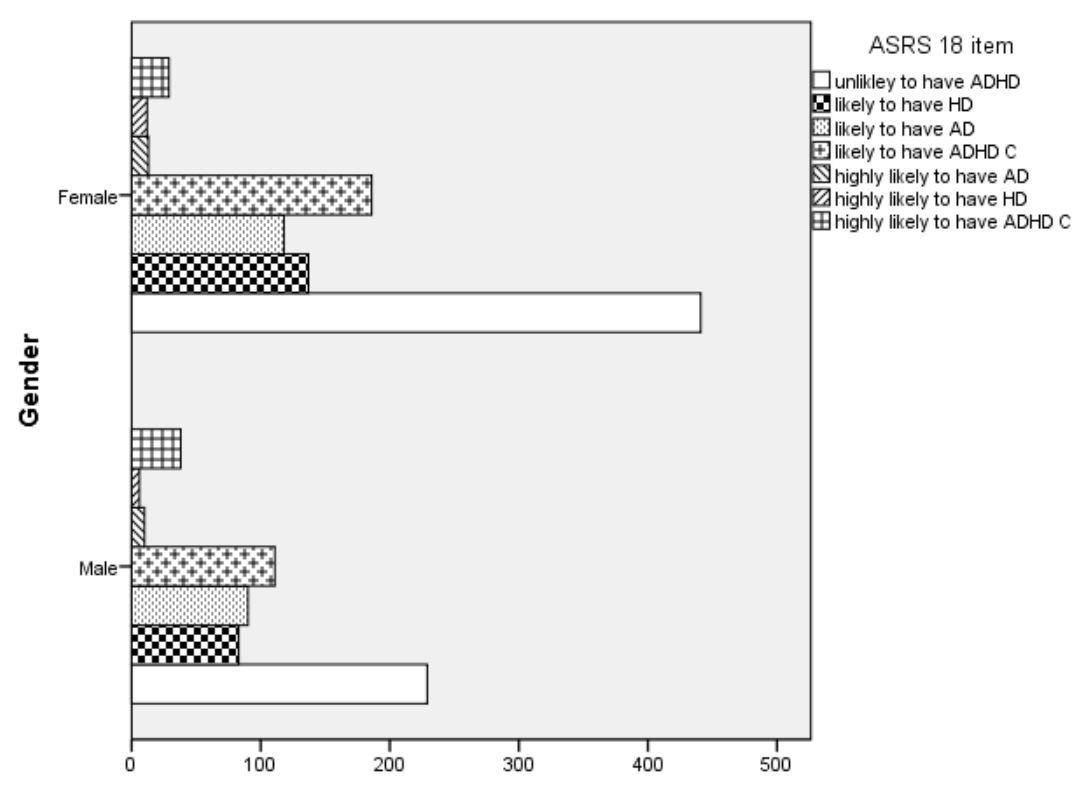

Figure 2A. The ASRS-v1.1 symptom checklist(18 item)

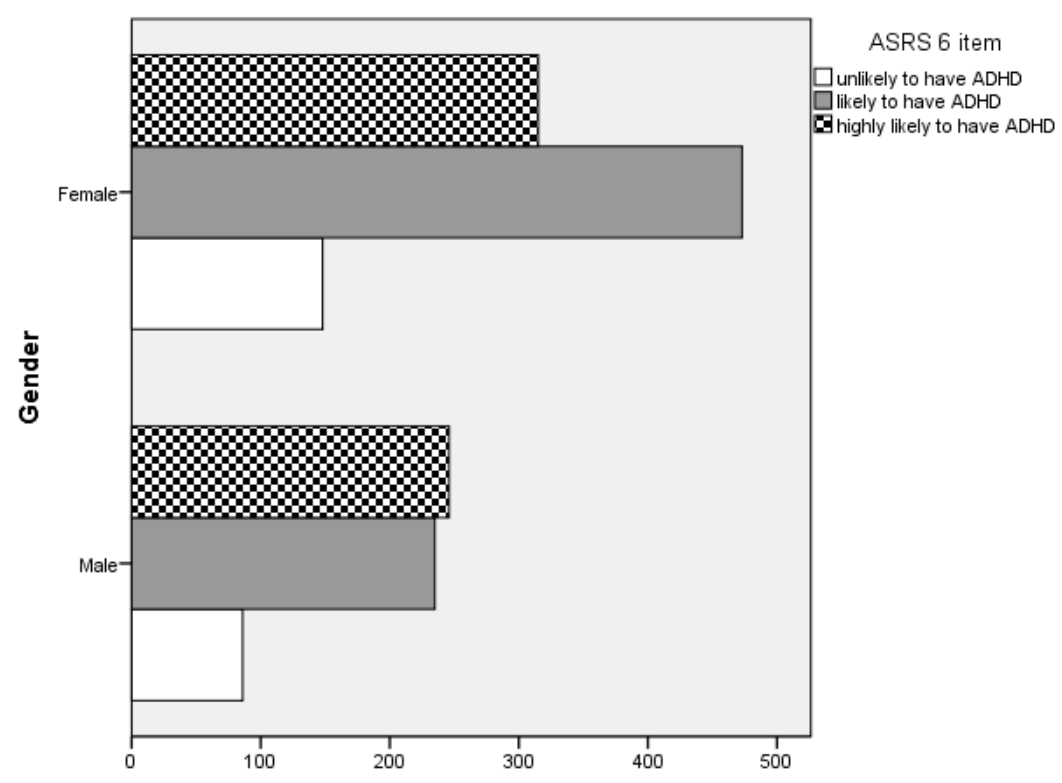

Figure 2B. The ASRS-v1.1 screener(6 item)

Figure 2. The unweighted prevalence of ADHD according to gender distribution 


\section{Discussion}

The first aim of the present study was to investigate the utility and psychometric properties of the Adult ADHD Self-Report Scale (ASRS-v1.1) in a Hungarian sample, with participants from Romania and from Hungary.

Previous studies reported mixed results regarding the ASRS-v1.1 symptom checklist (18 item) compared to the ASRS-v1.1 screener (6 item). According to the results of Kessler et al. (2005) the unweighted 6 item ASRS-v1.1 screener outperformed the unweighted 18 item symptom checklist in sensitivity $(68,7 \%$ v. $56,3 \%)$, specificity $(99,5 \%$ v. $98,3 \%)$, total classification accuracy (97,9\% v. 96,2\%). Results of Kiatrungrit et al. (2017) based on Thai version of the ASRS-v1.1, the Area Under Curve for 6 item was AUC=.80 (95\% CI: .68-.92), while for the 18 item was AUC $=.71(95 \%$ CI: .55-.86). These results confirmed Kessler et al (2005) results.

The current study's results are not consistent with previous studies. The Area Under Curve for the 6 item was $\mathrm{AUC}=.99$ (95\% CI: .98-1.00), while for the 18 item was AUC=1.00. Sensitivity for the 6 item ASRS-v1.1 was 93\% and 100\% specificity (for scores above 12). In addition, sensitivity for the 18 item ASRS-v1.1 was $100 \%$ and $99 \%$ specificity (for scores above 24).

However, in general, good test-retest reliability and internal consistency of the translated versions of the ASRS-v1.1 were reported. Psychometric properties of the Korean version of the ASRS-v.1.1 were good (Kim et al., 2013): the instrument had good internal consistency (indicated by high Cronbach alpha value $\alpha=.885$ ) and test-retest reliability $(\alpha=.878)$.

In addition, a subsequent exploratory factor analysis indicated that a two factor solution provided the best fit. Furthermore, the Chinese version of the ASRS-v1.1 (Yeh et al., 2008) showed good concordance (ICC $=.80 \mathrm{v}$. .85) and internal consistency (Cronbach alpha $\alpha=.83$ v. .91) and moderate to high correlations (Pearson's correlations $=.37$ v. .66) between ASRSv1.1 subscales and the WURS. In addition, Kiatrungrit et al. (2017) reported also good psychometric properties of the Thai version of the 18 item ASRS-v1.1. Results showed good internal consistency (indicated by high Cronbach alpha value $\alpha=.92$, respectively $\alpha=.87$ for inattentive scale, $\alpha=.84$ for hyperactive/impulsive scale). Moreover, Stanton et al. (2018) examined the factor structure of the adult ASRS-v1.1. Results indicated that the ASRS's items define a bifactor structure with specific dimensions of inattentiveness, motor hyperactivity/impulsivity and verbal hyperactivity/impulsivity.

According to the results of the current study, the subscales of the 18-item ASRS-v1.1 Symptom Checklist exhibited good internal consistency indicated by acceptable Cronbach's alpha: inattention subscale $\alpha=.84$, hyperactivity subscale $\alpha=.80$, total $\alpha=.88$. Despite this, the psychometric properties of the ASRS-v1.1 screener were less adequate than the 18 item ASRS. This version had fair internal consistency: inattention subscale $\alpha=.77$, hyperactivity subscale $\alpha=.54$, total $\alpha=.72$. Internal consistency values are close to results of several previous studies (Kim et al., 2013, Yeh et al., 2008, Kiatrungrit et al., 2017). In addition, results of previous studies (Stanton et al., 2018) regarding factor structure were also confirmed, the 2 factor structure model was adequate. The model fit indices in the current study were higher for the ASRS-v1.1 screener (6 item).

The secondary aim of the current study was to assess prevalence of adult ADHD in Hungarian adults from Romania and from Hungary. The current study's results show 1.5\% unweighted prevalence of attention disorder based on the 18 item ASRS-v1.1 symptom checklist. In addition, the prevalence of hyperactivity disorder was $1.2 \%$, reported mostly by female participants $(0.8 \%)$. Moreover, the prevalence of ADHD Combined type was $4.5 \%$, mostly male $(2.5 \%)$. A total prevalence of $7.2 \%$ of Hungarian adults with ADHD (all type). 
Based on the 6 item ASRS-v1.1 screener the unweighted prevalence of the ADHD symptoms was $37.3 \%(\mathrm{~N}=561)$, allocated to the highly likely to have ADHD group.

Previous studies reported similar results. The prevalence of ADHD for adults from Hungary based on DSM-IV and DSM-5 criteria varied from 5.4\% (CI 95\%: 2.4-8.3) to 7.6\% (CI 95\%: 4.1-11.1), slightly higher for DSM-5 (van de Glind et al., 2014). Bitter et al. (2017) reported prevalence of 1.3 to $4.6 \%$ (threshold-subthreshold) of adult ADHD in Hungary. Crude prevalence estimates adjusted for the specificity and sensitivity data of the screener were $1.35 \%$ in the 'DSM-IV' group.

Multiply imputed prevalence estimates of DSM-IV/CIDI of adult ADHD in Romania was $0.6 \%$, based on 940 adults in the total sample (Fayyad et al., 2017).

In conclusion, the current study's results suggest that the 18 item ASRS-v1.1 Hungarian version is a good symptom checklist for the assessment of adult ADHD, indicated by the good psychometric properties of the scale. In addition, the ASRS-v1.1 screener can be considered a fair screening tool for identifying symptoms of ADHD among normal population.

\section{References}

[1] Adler, L.A., Spencer, T., Faraone, S.V., Kessler, R.C., Howes, M.J., Biederman, J., et al. (2006). Validity of pilot Adult ADHD Self-Report Scale (ASRS) to Rate Adult ADHD symptoms. Annals of Clinical Psychiatry; 18:145-148.

[2] American Psychiatric Association - APA (2000). Diagnostic and statistical manual of mental disorders (4th ed.). Washington, DC, 85-93.

[3] Bentler, P.M. (1990). Comparative fit indexes in structural models. Psychological Bulletin, 107: 238-246.

[4] Bitter I., Simon V., Bálint S., Mészáros A., Czobor P.(2010). How do different diagnostic criteria, age and gender affect the prevalence of attention deficit hyperactivity disorder in adults? An epidemiological study in a Hungarian community sample. European Achieves of Psychiatry and Clinical Neuroscience, 260(4):287-96. http://doi.org/10.1007/s00406009-0076-3.

[5] Browne, M.W., Cudeck, R. (1989). Single sample cross-validation indices for covariance structures. Multivariate Behavioral Research; 24:445-455.

[6] Carlucci, S., Ivanova, I., Bissada, H., Tasca, G.A. (2017). Validity and reliability of the attention deficit hyperactivity disorder self-report scale (ASRS-v1.1) in a clinical sample with eating disorders. Eating Behaviors, 26:148-154. http://doi.org/10.1016/j.eatbeh.2017.03.010.

[7] Daigre Blanco, C., Ramos-Quiroga, J.A., Valero, S., Bosch, R., Roncero, C., Gonzalvo, B., et al. (2009). Adult ADHD Self-Report Scale (ASRS-v1.1) symptom checklist in patients with substance use disorders. Actas Esp Psiquiatry, 37: 299-305.

[8] Das, D., Cherbuin, N., Butterworth, P., Anstey, K.J., Easteal, S. (2012). A populationbased study of attention deficit/hyperactivity disorder symptoms and associated impairment in middle-aged adults. PLoS One, 7:e31500.

[9] de Zwaan, M., Gruss, B., Muller, A., Graap, H., Martin, A., Glaesmer, H., et al. (2012). The estimated prevalence and correlates of adult ADHD in a German community sample. European Achieves of Psychiatry and Clinical Neuroscience, 262: 79-86.

[10] Faraone, S.V., Antshel, K.M. (2008). Diagnosing and treating attentiondeficit/hyperactivity disorder in adults. World Psychiatry, 7:131-136. http://doi.org/10.1002/j.2051-5545.2008.tb00179.x

[11] Faraone, S.V., Sergeant, J., Gillberg, C., Biederman, J. (2003). The worldwide prevalence of ADHD: is it an American condition? World Psychiatry, 2: 104-113. 
[12] Fayyad, J., Sampson, N.A., Hwang, I., Adamowski, T., Aguilar-Gaxiola, S., AlHamzawi, A., et al. Kessler, R. C. (2017). The descriptive epidemiology of DSM-IV Adult ADHD in the World Health Organization World Mental Health Surveys. Attention Deficit Hyperactivity Disorder; 9(1), 47-65. http://doi.org/10.1007/s12402-016-0208-3.

[13] George, D., Mallery, M. (2010). SPSS for Windows Step by Step: A Simple Guide and Reference, 17.0 update (10a ed.). Boston: Pearson.

[14] Kessler, R.C., Adler, L., Ames, M., Demler, O., Faraone, S., Hiripi, E., et al. (2005). The World Health Organization Adult ADHD Self-Report Scale (ASRS): a short screening scale for use in the general population. Psychological Medicine, 35: 245-256.

[15] Kessler, R.C., Adler, L.A., Barkley, R., Biederman, J., Conners, C.K., Demler, O., et al. (2006). The prevalence and correlates of adult ADHD in the United States: results from the National Comorbidity Survey Replication. American Journal of Psychiatry, 163:716723. http://doi.org/10.1176/appi.ajp.163.4.716

[16] Kessler, R.C., Adler, L.A., Gruber, M.J., Sarawate, C.A., Spencer, T., Van Brunt, D L. (2007). Validity of the World Health Organization Adult ADHD Self-Report Scale (ASRS) Screener in a representative sample of health plan members. International Journal of Methods in Psychiatric Research, 16: 52-65. http://doi.org/10.1002/mpr.208

[17] Kiatrungrit, K., Putthisri, S., Hongsanguansri, S., Wisajan, P., Jullagate, S. (2017). Validity and Reliability of Adult ADHD Self-Report Scale Thai Version (ASRS-V1.1 TH). Shanghai Achieves of Psychiatry, 29(4): 218-227. doi: http://dx.doi.org/10.11919/j.issn.1002-0829.217021.

[18] Kim, J.-H., Lee, E.-H., Joung, Y.-S. (2013). The WHO Adult ADHD Self-Report Scale: Reliability and Validity of the Korean Version. Psychiatry Investigation, 10(1), 4146. http://doi.org/10.4306/pi.2013.10.1.41

[19] Morin, A., Tran, A., Caci, H. (2016). Factorial validity of the ADHD Adult Symptom Rating Scale in a French community sample: Results from the ChiP-ARD Study. Journal of Attention Disorders, 20, 530-541. http://doi.org/10.1177/1087054713488825.

[20] Pedrero, E. J., Puerta, C. (2007). The ASRS v.1.1 as a screening tool for the assessment of the attention-deficit/hyperactivity disorder in adults under addictive behaviours treatment: Psychometric properties and estimated prevalence. Addiciones, 19, 393-407.

[21] Simon V., Czobor P., Balint S., Meszaros A., Bitter I. (2009). Prevalence and correlates of adult attention-deficit hyperactivity disorder: meta-analysis. British Journal of Psychiatry; 194: 204-211.

[22] Stanton, K., Forbes, M.K., Zimmerman, M. (2018). Distinct dimensions defining the Adult ADHD Self-Report Scale: Implications for assessing inattentive and hyperactive/impulsive symptoms. Psychological Assessment. http://doi.org/10.1037/pas0000604. [Epub ahead of print]

[23] Steiger, J.H., Lind, J.C. (1980). Statistically based tests for the number of common factors. Paper presented at the annual meeting of the Psychometric Society, Iowa City, IA.

[24] Van de Glind, G., Konstenius, M., Koeter, M. W. J., van Emmerik-van Oortmerssen, K., Carpentier, P.-J., Kaye, S., ... IASP Research Group. (2014). Variability in the prevalence of adult ADHD in treatment seeking substance use disorder patients: Results from an international multi-center study exploring DSM-IV and DSM-5 criteria. Drug and Alcohol Dependence, 134, 158-166. http://doi.org/10.1016/j.drugalcdep.2013.09.026.

[25] Yeh, C.B., Gau, S.S., Kessler, R.C., Wu, Y.Y. (2008). Psychometric properties of the Chinese version of the adult ADHD Self-report Scale. International Journal of Methods in Psychiatric Research, 17: 45-54. http://doi.org/10.1002/mpr.241 